\title{
A Synthesis of Peer-Reviewed Literature on Team-Coordinated and Delivered Early Supported Discharge After Stroke
}

\author{
Matthew J. Meyer, Robert Teasell, Amardeep Thind, John Koval, Mark Speechley
}

\begin{abstract}
This review aimed to summarize data from peer-reviewed studies of team-coordinated and delivered early supported discharge (ESD) for postacute, poststroke rehabilitation. A systematic review was performed in Medline, Embase, and CINAHL for appropriate studies. Information on program details and patient cohorts was synthesized. All programs sought patients with mild-to-moderate functional impairment and minimal cognitive impairment (often based on Barthel Index and Mini-Mental State Examination scores, respectively). All also included at least one subjective admission criterion related to rehabilitation suitability or the suitability of the home environment. Based on the identified studies, ESD programs can assume that $15 \%$ of patients screened for ESD will be eligible and care should be provided for 4 to 5 weeks postdischarge. Although the benefits of team-coordinated and delivered ESD poststroke have been well-documented, this review may be helpful for clinicians, administrators, and policy makers looking to establish or refine an ESD program for stroke.
\end{abstract}

RÉSUMÉ: Synthèse de la littérature revue par des pairs sur le congé hospitalier précoce avec soutien coordonné et fourni par une équipe de personnel soignant après un accident vasculaire cérébral. L'objectif de cette revue était de résumer les données des études revues par des pairs sur le congé hospitalier précoce avec soutien (CHPS) coordonné et fourni par une équipe de personnel soignant pour la réadaptation post aiguë après un accident vasculaire cérébral (AVC). Nous avons effectué une revue systématique dans les bases de données Medline, Embase et CINAHL pour identifier les études pertinentes. Nous avons effectué une synthèse de l'information sur les détails des programmes et sur les cohortes de patients. Tous les programmes visaient des patients ayant un déficit fonctionnel de léger à modéré et un déficit cognitif minime (souvent basé sur le score à l'indice de Barthel et au Mini-Mental State Examination respectivement). Tous incluaient également au moins un critère d'admission subjectif en lien avec l'adéquation du sujet et de son environnement domiciliaire à la réadaptation. D'après les études identifiées, les programmes de CHPS peuvent présumer que $15 \%$ des patients dépistés pour un CHPS y seront éligibles et que les soins devraient être prodigués pendant 4 à 5 semaines après le congé. Bien que les bénéfices du soutien coordonné et fourni par une équipe de personnel soignant après un CHPS aient été bien documentés, cette revue peut aider les cliniciens, les administrateurs et les décideurs qui prévoient établir ou perfectionner un tel programme pour l'AVC.

Keywords: Early supported discharge, health services research, stroke

doi:10.1017/cjn.2015.343

Can J Neurol Sci. 2016; 43: 353-359

\section{INTRODUCTION}

The World Health Organization estimates that 15 million people experience a stroke each year, 5 million of whom are left with permanent disability. ${ }^{1}$ Despite an abundance of evidence suggesting that poststroke rehabilitation can improve patient recovery and reduce disability, ${ }^{2}$ debate still remains about where and when these services are best provided. Early supported discharge (ESD), in which rehabilitative care is provided in the community as an alternative to remaining in the hospital, has gained popularity around the world as a less costly way to rehabilitate moderately and mildly disabled stroke patients. Trials performed to date on ESD suggest that, when provided to appropriate patients, it can reduce the risk of death or dependency, ${ }^{3}$ admission to institutional care ${ }^{3}$ length of hospital stay, ${ }^{3-6}$ and the overall cost of services ${ }^{3,5,7}$ compared with traditional in-hospital rehabilitation. Accordingly, ESD has been included in the Canadian Best-Practice Recommendations for Stroke. ${ }^{8}$ If policy makers and health care providers hope to adhere to best-practice principles in stroke management, ESD is an essential component.

The most comprehensive review of poststroke ESD was done by the Cochrane Collaboration in 2012, which performed pooled analyses of 14 randomized-controlled trials compared with usual care. ${ }^{3}$ In this review, three forms of ESD intervention were identified: ESD team coordination and delivery, ESD team coordination only,

From the Department of Epidemiology and Biostatistics, Western University London, Ontario (MJM, AT, JK, MS); London Health Sciences Centre London, Ontario (MJM); Aging, Rehabilitation and Geriatric Care Research Centre, Lawson London, Ontario (MJM, RT); Department of Physical Medicine and Rehabilitation, Schulich School of Medicine and Dentistry London, Ontario (RT); Department of Physical Medicine and Rehabilitation, St. Joseph's Healthcare London, Ontario (RT); Interfaculty Program in Public Health, Western University London, Ontario (AT, MS); Department of Family

Medicine, Schulich School of Medicine and Dentistry London, Ontario (AT). Received June 25, 2015. Final Revisions Submitted August 25, 2015. Correspondence to: Matthew Meyer, Parkwood Institute, Rm 3019a, 550 Wellington Road, London, Ontario, Canada N6C 0A7. Email: Matthew.Meyer@sjhc.london.on.ca 
and no ESD team. Statistically significant differences between ESD and conventional care were only noted for the two primary outcomes of death or institutionalization, and death or dependency among studies where ESD was team-coordinated and delivered (i.e. the hospital-based ESD team both arranged for and provided services). However, no pooled description of these studies was provided. The authors of this review noted that further research should be completed to "define the important characteristics of effective ESD services." 3

In a consensus report on the topic, an international panel of experts on ESD unanimously agreed that specific eligibility criteria for early supported discharge should be used and that eligibility decisions should be based in part on the patient's level of disability and medical stability. ${ }^{4}$ The panel also unanimously agreed that identification of patients suitable for ESD should be made by the ESD team and that flexibility in the criteria is essential. However, the panel did not reach unanimous agreement about what role factors, such as Barthel Index (BI) scores, ability to transfer from bed to chair, or cognitive function. should play in decisions about patient eligibility for ESD.

The objective of this study was to perform a review of the peer-reviewed literature on poststroke ESD that focused on programs providing best practice care (i.e. those that were ESD team-coordinated and delivered). Study inclusion was expanded beyond randomized controlled trials. Information related to the interventions evaluated, the inclusion/exclusion criteria used, the resulting cohort of patients admitted, and the outcomes observed in identified studies was summarized.

\section{METHODS}

A systematic review of the literature was performed in three electronic databases (Medline-OVID, Embase-OVID, CINAHLEBSCO Host) for peer-reviewed journal articles evaluating teamcoordinated and delivered postacute ESD programs for poststroke rehabilitation. Studies published between January 1980 and August 2014 were considered for inclusion. The complete search strategy is presented in Appendix A, but briefly included subject and keyword searches of terms including "stroke," "cerebrovascular accident," "rehabilitation," "early supported discharge," "home care services," and "community care." Titles and abstracts were reviewed and pertinent studies, systematic reviews, and meta-analyses were retrieved. All identified works were reference-searched for additional studies. Studies were included for data extraction if:

- Only patients with primary diagnosis of stroke or cerebrovascular accident were included

- The intervention under study was a team-coordinated and delivered postacute ESD program for poststroke rehabilitation defined as follows:

- ESD team coordinated and delivered programs: identified according to the definition used by the Cochrane Collaboration ${ }^{3}$ - Postacute: programs where the patients under consideration had been admitted to hospital for their acute medical management (i.e. not hospital-at-home)

- Poststroke rehabilitation: patients included in the intervention would otherwise have been admitted to postacute in-hospital rehabilitation

- Inclusion/exclusion criteria were reported
Data extraction consisted of two phases: program description and patient data. Program description included a brief summary of the structure of the ESD program, a description of the control group, and a list of the inclusion/exclusion criteria used to identify suitable candidates. Additional program-specific data included the mean hospital length of stay in the intervention group before discharge, and the proportion of screened patients deemed suitable for ESD (including patients who declined participation but would otherwise have been included).

Extracted patient data began with a description of the cohort included in each trial: mean age, percent female, and proportion with hemorrhagic stroke. This was followed by information on any objective measure of physical, cognitive, social, or psychological status assessed within 48 hours of discharge to the ESD program. Finally, all reported outcome measures at the longest period of follow-up were noted along with results of statistical comparison to the control group.

\section{Results}

A flow chart summarizing results from the literature review is presented in Figure 1. In total, 641 journal articles were screened. Initially, 490 articles were excluded by title (many articles specifically dealt with cardiac rehabilitation and could be excluded on first glance). Ninety-eight articles were removed based on the abstract alone and 45 after review of the full paper. Of these 45 articles, 13 described an ESD program that was not team coordinated and delivered, postacute, or an alternative to inpatient rehabilitation. Of the remaining exclusions, 12 were reviews, 8 were economic analyses of included trials, 5 were follow-up studies of included trials, 5 did not evaluate an ESD program, 1 was a commentary, and 1 did not include stroke patients. No additional studies were located in the reference lists of the identified reviews. In total, eight studies were included for further assessment. ${ }^{6,9-15}$

A summary of the programs explored in the studies of a team coordinated and delivered ESD program is provided in Table 1. All teams included a physiotherapist (PT) and occupational therapist (OT) and most included access to a speech language pathologist (SLP). Most teams also included access to a social worker (SW) or nurse. Inclusion and exclusion criteria frequently focused on patients who had physical impairments that could benefit from rehabilitation, but most also included criteria that excluded patients with serious cognitive impairment or comorbidity that would preclude them from benefiting from rehabilitation. All studies also included some form of subjective criteria to allow clinicians an opportunity to exclude patients they judged to be unsuitable. In studies in which it was reported, the weighted average proportion of acute admissions deemed eligible for ESD was $19 \%$ (range, $10 \%$ to $46 \%$ ), with the proportion generally decreasing in more recent studies. The typical period of recruitment into ESD was between 8 and 14 days poststroke, with only two exceptions. ${ }^{9,15}$ Mean length of participation in the ESD programs ranged from 30 days to 4 months across studies; however, this was generally shorter in more recent studies (post-2000), where all but one ${ }^{9}$ reported ESD duration between 4 and 5 weeks.

A summary of information on the cohort of patients included in the identified trials and their corresponding outcomes is provided in Table 2. The average age of patients was approximately 70 years in all trials (range, 68 to 73 ) and in all but one study, ${ }^{11}$ there were more men than women included. In studies in which it 
Table 1: Summary of program descriptions in identified studies of team-coordinated and delivered postacute ESD for stroke rehabilitation

\begin{tabular}{|c|c|c|c|c|c|c|c|}
\hline Study, year (design) & Composition of ESD team & Control & Inclusion criteria & Exclusion criteria & $\begin{array}{l}\text { Patients included/ } \\
\text { patients screened }\end{array}$ & Duration of ESD & $\begin{array}{l}\text { ESD patient } \\
\text { HLOS (days) }\end{array}$ \\
\hline $\begin{array}{l}\text { Anderson, } 2000^{6} \\
(\mathrm{RCT})\end{array}$ & $\begin{array}{l}\text { Program coordinator (OT), } \\
\text { rehabilitation consultant, } \\
\text { PT, OT, SLP, SW, } \\
\text { rehabilitation nurse }\end{array}$ & $\begin{array}{l}\text { Inpatient rehabilitation, } \\
\text { discharge planning and } \\
\text { follow-up care as an } \\
\text { outpatient or in community }\end{array}$ & $\begin{array}{l}\text { Medically stable, suitable for } \\
\text { discharge, suitable home } \\
\text { environment, community } \\
\text { rehabilitation team } \\
\text { available, GP to provide } \\
\text { medical care }\end{array}$ & $\begin{array}{l}\text { Subarachnoid hemorrhage, } \\
\text { insufficient physical and } \\
\text { cognitive function to perform } \\
\text { rehabilitation, lack of } \\
\text { caregiver consent }\end{array}$ & $112 / 398(28 \%)$ & 5 weeks median & 13 median \\
\hline $\begin{array}{l}\text { Donnelly, } 2004^{9} \\
\text { (RCT) }\end{array}$ & $\begin{array}{l}\text { Coordinator, OT, PT, SLP, } \\
\text { rehabilitation assistant }\end{array}$ & $\begin{array}{l}\text { Hospital rehabilitation with } \\
\text { day hospital follow-up }\end{array}$ & $\begin{array}{l}<4 \text { weeks poststroke, } \\
\text { potential to benefit from } \\
\text { rehabilitation }\end{array}$ & $\begin{array}{l}\text { Nursing or residential home } \\
\text { resident, preexisting } \\
\text { disability that precluded } \\
\text { rehabilitation }\end{array}$ & $118 / 896(13 \%)$ & 3 months & 42 mean \\
\hline $\begin{array}{l}\text { Holmqvist, } 1998^{10} \\
\text { (RCT) }\end{array}$ & $\begin{array}{l}\text { PT, OT, SLP, SW } \\
\text { (consult), coordinator }\end{array}$ & $\begin{array}{l}\text { Routine inpatient and/or day } \\
\text { hospital/outpatient } \\
\text { rehabilitation }\end{array}$ & $\begin{array}{l}\text { Acute stroke, Katz ADL A-E, } \\
\text { MMSE > 23, impaired } \\
\text { motor capacity (LS) and/or } \\
\text { dysphasia (RAT), no other } \\
\text { comorbidity likely to } \\
\text { shorten life expectancy }\end{array}$ & $\begin{array}{l}<5 \text {-day HLOS, progressive } \\
\text { stroke, subdural hematoma, } \\
\text { subarachnoid hemorrhage, } \\
\text { massive perceptual deficit, } \\
\text { renal/heart/respiratory } \\
\text { failure, nonstroke epilepsy, } \\
\text { alcoholism, psychiatric } \\
\text { disease }\end{array}$ & $86 / 900(10 \%)$ & 3-4 months & 14 mean \\
\hline $\begin{array}{l}\text { Ljungberg, } 2001^{11} \\
\text { (non-RCT) }\end{array}$ & $\begin{array}{l}\text { Nurse, nurse's aide, OT, } \\
\text { PT, social welfare } \\
\text { officer, neurologist }\end{array}$ & Inpatient rehabilitation clinic & $\begin{array}{l}\text { Expected rehabilitation time } \\
<4 \text { weeks, transfer from } \\
\text { chair to bed with 1-person } \\
\text { assist }\end{array}$ & $\begin{array}{l}\text { Dementia, dysphagia, cannot } \\
\text { communicate via telephone } \\
\text { or alarm bell even with } \\
\text { assistance of a relative }\end{array}$ & NR & 4 weeks & 8 mean \\
\hline Mayo, $2000^{12}(\mathrm{RCT})$ & $\begin{array}{l}\text { Nurse, PT, OT, SLP, } \\
\text { dietitian }\end{array}$ & $\begin{array}{l}\text { Usual care (hospital and } \\
\text { community rehabilitation) }\end{array}$ & $\begin{array}{l}\text { Persistent motor deficits, able } \\
\text { and willing caregiver }\end{array}$ & $\begin{array}{l}>1 \text { person assist to walk after } \\
28 \text { days poststroke, cognitive } \\
\text { impairment (SPMSQ), } \\
\text { coexisting conditions } \\
\text { affecting independence }\end{array}$ & $194 / 1542(13 \%)$ & 4 weeks & 9.8 mean \\
\hline $\begin{array}{l}\text { Pessah-Rasmussen, } \\
2009^{13} \text { (non-RCT) }\end{array}$ & $\begin{array}{l}\text { PT, OT, neurologist } \\
\text { (SLP, SW, nurse, } \\
\text { neuropsychology when } \\
\text { necessary) }\end{array}$ & $\begin{array}{l}\text { Registry-identified non-ESD } \\
\text { patients }\end{array}$ & $\begin{array}{l}\text { Need for training in personal } \\
\text { or extended activities ADL }\end{array}$ & $\begin{array}{l}\text { Severe prestroke dementia, } \\
\text { alcohol or drug abuse, } \\
\text { unsuitable home conditions, } \\
\text { cognitive impairment where } \\
\text { insight/communication lead } \\
\text { to safety concerns }\end{array}$ & NR & $\begin{array}{l}\text { 1997: 43-day mean } \\
\text { 2005: 30-day } \\
\text { mean }\end{array}$ & $\begin{array}{l}\text { 1997: 18-day mean } \\
\text { 2005: 10-day } \\
\text { mean }\end{array}$ \\
\hline $\begin{array}{l}\text { Rodgers, } 1997^{14} \\
\text { (RCT) }\end{array}$ & $\begin{array}{l}\text { Service coordinator (OT or } \\
\text { PT), OT, PT, SLP, SW, } \\
\text { OT technician }\end{array}$ & $\begin{array}{l}\text { Conventional care (hospital } \\
\text { and community rehab) }\end{array}$ & $\begin{array}{l}\text { Newcastle resident, } \\
\text { medically stable, BI } 5 \text { to } 19 \\
72 \text { hours' poststroke }\end{array}$ & $\begin{array}{l}\text { Residential or nursing home } \\
\text { resident, OHS } 0 \text { to } 3 \text { before } \\
\text { stroke, other condition } \\
\text { precluding rehabilitation }\end{array}$ & $119 / 402(30 \%)$ & 9 weeks median & 13 median \\
\hline Rudd, $1997^{15}$ (RCT) & $\begin{array}{l}\text { PT, OT, SLP, therapy aide, } \\
\text { physician consult }\end{array}$ & $\begin{array}{l}\text { Conventional care (hospital } \\
\text { and outpatient } \\
\text { rehabilitation) }\end{array}$ & $\begin{array}{l}\text { Able to transfer } \\
\text { independently (if living } \\
\text { alone) else with assistance }\end{array}$ & Lived too far for team to visit & $302 / 660(46 \%)$ & Up to 3 months & 34 mean \\
\hline
\end{tabular}

$\mathrm{ADL}=$ activities of daily living; GP = general practitioner; HLOS = hospital length of stay; LS = Lindmark scale; NR = not reported; OHS = Oxford handicap scale; RAT = Reinvang aphasia test RCT $=$ randomized controlled trial; SPMSQ $=$ Short Portable Mental Status Questionnaire; SLP $=$ speech language pathologist; TIA $=$ transient ischemic attack 
Table 2: Summary of patient populations and outcomes in identified studies of team-coordinated and delivered postacute early supported discharge for stroke rehabilitation

\begin{tabular}{|c|c|c|c|c|c|}
\hline Study, year (design) & Age (mean) & Female $(\%)$ & $\begin{array}{l}\text { Hemorrhagic } \\
\text { stroke }(\%)\end{array}$ & Patient variables measured at randomization or discharge (mean) & Outcome measures and results $^{\alpha}$ \\
\hline Anderson, $2000^{6}(\mathrm{RCT})$ & 72 & 38 & 10 & $\begin{array}{l}\text { All median: BI 85/100, MMSE 28/30, AAP (domestic chores 53/100, } \\
\text { household 56/100, service 50/100, social 46/100), GHQ (somatic 5/10, } \\
\text { anxiety 4/10, social 8/10, depression 0/10) }\end{array}$ & $\begin{array}{l}\text { 6-month: SF-36 (NS), BI (NS), NHP (NS), satisfaction (NS), AAP } \\
\text { (NS), MFAD (NS), death (NS), falls (NS) }\end{array}$ \\
\hline Donnelly, $2004^{9}$ (RCT) & 68 median & NR & NR & $\begin{array}{l}\text { BI 14/20, NEADL 6/21, 10-m timed walk } 21 \text { seconds, EuroQol 59/100, } \\
\text { SF-36 physical 35/100, SF-36 Mental 48/100, Quality of Life 17/27 }\end{array}$ & $\begin{array}{l}\text { 1-year: BI (NS), NEADL (NS), 10-m timed walk (NS), EuroQol (NS), } \\
\text { SF-36 Physical (NS), SF-36 Mental (NS), QoL (NS), patient } \\
\text { satisfaction (+), overall satisfaction (+), carer strain (NS) }\end{array}$ \\
\hline $\begin{array}{l}\text { Holmqvist, } 1998^{10} \\
\quad(\text { RCT })\end{array}$ & 71 & 46 & 7 & $\begin{array}{l}\text { MMSE } 27 / 30 \text {, motor capacity (arm 50/57, leg } 34 / 36 \text {, coordination } 8 / 12 \text {, } \\
\text { mobility } 25 / 27 \text {, balance } 15 / 21 \text {, total } 131 / 153 \text { ), 10-m walk test } \\
14 \text { seconds (median), neurological score } 49 / 58 \text {, aphasia quotient } 24 / 100\end{array}$ & $\begin{array}{l}\text { 3-month: KATZ ADL (NS), BI (NS), FAI (NS), Lindmark motor } \\
\text { capacity (+ coordination, others NS), 9-hole peg test (NS), 10-m } \\
\text { walk (NS), aphasia quotient (NS), falls (NS), SIP (+ psychosocial, } \\
\text { NS others) }\end{array}$ \\
\hline $\begin{array}{l}\text { Ljungberg, } 2001^{11} \\
\text { (non-RCT) }\end{array}$ & 72 & 56 & 9 & $\begin{array}{l}\text { FIM (hygiene } 4.9 / 7 \text {, bathing } 2.1 / 7 \text {, dressing upper } 4.8 / 7 \text {, dressing lower } \\
3.7 / 7 \text {, toileting } 4.1 / 7 \text {, feeding } 5.4 / 7 \text {, transfer chair/bed } 4.5 / 7 \text {, transfer } \\
\text { toilet } 4.8 / 7 \text {, transfer tub shower } 2.4 / 7 \text {, locomotion } 3.4 / 7 \text {, locomotion } \\
\text { stairs } 2.5 / 7 \text {, comprehension } 5.6 / 7 \text {, expression } 5.4 / 7 \text {, problem solving } \\
4.5 / 7 \text {, memory } 5.5 / 7\end{array}$ & $\begin{array}{l}\text { 4-week: modified QPP (+ activity level, staff importance, } \\
\text { participation, others all NS) }\end{array}$ \\
\hline Mayo, $2000^{12}(\mathrm{RCT})$ & 70 & 33 & NR & CNS 8.9/11.5, STREAM 82.3/100, TUG 23.3 seconds, BI 84.6/100 & $\begin{array}{l}\text { 3-month: SF-36 (+ physical, NS Mental), STREAM (NS), TUG (NS), } \\
\text { BI (NS), OARS-IADL (+), RNL (NS) }\end{array}$ \\
\hline $\begin{array}{l}\text { Pessah-Rasmussen, } \\
2009^{13} \text { (non-RCT) }\end{array}$ & 73 & 48 & 15 & $\begin{array}{l}1997 \text { Katz ADL (A, 6\%; B, } 18 \% \text {; C, 17\%; D, 7\%; E, 24\%; F, 7\%) 2005: } \\
\quad \text { Katz ADL (A, 30\%; B, 21\%, C, 13\%; D, 3\%; E, 2\%; F, 4\%; G, 4\%) }\end{array}$ & No comparison to control reported \\
\hline Rodgers, $1997^{14}(\mathrm{RCT})$ & 73 median & 43 & NR & BI 15/20 median & $\begin{array}{l}\text { 3-month: survival (NS), placement (NS), readmission (NS), NEADL } \\
\text { (NS), OHS (NS), WDI (NS), DCGHS (NS), GHQ (NS) }\end{array}$ \\
\hline Rudd $1997^{15}$ (RCT) & 70 & 45 & NR & $\begin{array}{l}\text { BI 15/20, Frenchay aphasia } 18 / 20 \text {, MMSE 21/30, MI 83/100, 5-m timed } \\
\text { walk } 15 \text { seconds, NHP } 11 / 100\end{array}$ & $\begin{array}{l}\text { 1-year: MI (NS), MMSE (NS), FAS (NS), BI (NS), RADL (NS), } \\
\text { HADS (- anxiety, NS depression), 5-m timed walk (NS), NHP (NS), } \\
\text { CSI (NS) }\end{array}$ \\
\hline
\end{tabular}

(+): Significantly better in ESD; (-): significantly better in control; ADL = activities of daily living; AAP = Adelaide Activities Profile; CNS $=$ Canadian Neurological Scale; DCGHS = Dartmouth Coop Global Health Status; FAI = Frenchay Activities Index; FAS = Frenchay Aphasia Scale; FIM = Functional Independence Measure; GHQ = General Health Questionnaire; GP = general practitioner; HADS = Hospital Anxiety and Depression Scale; MFAD = McMaster Family Assessment Device; MI = Mobility Index; NEADL = Nottingham Extended Activities of Daily Living; NHP = Nottingham Health Profile; NR = not reported; NS = no significant difference; OARS-IADL = Older Americans Resource Scale Instrumental ADL; OHS = Oxford handicap scale;

$\mathrm{QPP}=$ quality from the patient's perspective; $\mathrm{QoL}=$ quality of life; RNL = Reintegration to Normal Living; RADL = Rivermead ADL; SF-36 = Short Form 36; STREAM = Stroke Rehabilitation Assessment of Movement; TUG = Timed Up and Go; WDI = Wakefield Depression Inventory

${ }^{\alpha}$ Outcomes reported are intervention vs control comparisons at the longest point of follow-up. Subgroup analyses are not presented. Statistical significance is noted at $\mathrm{p}<0.05$. 
was reported, the majority of patients had experienced ischemic stroke; however, no study explicitly excluded hemorrhagic patients. None of the studies performed subgroup analyses to compare outcomes between stroke subtypes (e.g. ischemic vs hemorrhagic). Baseline and outcome measurement were performed by a variety of professionals including research associates, nurses, PT, OT, and SLP. A wide variety of functional measures at time of acute discharge were reported across the eight trials, only two of which were reported more than once: BI and Mini-Mental State Examination (MMSE). In trials reporting these scores, the mean BI score at discharge was 16/20 and the mean MMSE was 24/30. Rudd et al reported the most widely dispersed admission scores for both the BI and MMSE; in this study, 1 standard deviation in scores ranged from 11 to 19 in the $\mathrm{BI}$ and 14 to 28 on the MMSE. ${ }^{15}$ This wide variation in scores reflects more inclusive admission in this particular study that was not seen in the others. Across all eight trials, the majority of outcomes were either similar between ESD and the control group or in favour of ESD. Only once was an outcome demonstrated to be significantly better in the control group (1-year anxiety score on the Hospital Anxiety and Depression Scale $\left.^{15}\right)$.

\section{Discussion}

The benefits of ESD for poststroke rehabilitation have been well-documented and team-coordinated and delivered ESD has been identified as the optimal model of care. ${ }^{3}$ The objective of this review was to summarize the literature related to one of these ESD programs to assist decision makers looking to establish, or refine, a best-practice postacute ESD program for stroke rehabilitation. This was done by narrowing the focus of our search to team-coordinated and delivered ESD programs described in the peer-reviewed literature and expanding search criteria beyond randomized controlled trials. Eight studies met the inclusion criteria for this review, and the summary of program information and patient data demonstrate a number of similarities across studies that may be useful in planning an ESD program.

The composition of the ESD teams described in the eight identified trials was similar. The benefits of an interprofessional team poststroke have been well-documented, ${ }^{16}$ and it is evident that they have been recognized as critical components of a coordinated ESD program. All ESD teams included PT and OT as the core of their team and all but one also noted access to SLP. Most teams also included SW or nursing. Patients recovering from stroke (as well as their caregivers) often face challenges with anxiety, depression, and social isolation. One strength of a multidisciplinary rehabilitation team is that it can help patients address medical, physical, cognitive, and social issues concomittantly. ${ }^{16}$ Although therapists support functional recovery, ${ }^{2}$ nurses and SW play an important role in identifying social and emotional challenges and supporting patients as they recover from stroke. ${ }^{17-19}$ Social care has been identified as a particular challenge in securing timely discharge to $\mathrm{ESD},{ }^{20}$ which further highlights the importance of the inclusion of nurses and social workers in interprofessional ESD teams. Based on the results of this review, it would be our recommendation that PT, OT, SLP, SW, and nursing be considered as critical components of an effective ESD team.

In an international ESD consensus statement, experts agreed that decisions about admission to an ESD program after stroke should be made by members of the ESD team using specific eligibility criteria; however, they also noted the need for flexibility in this process. ${ }^{4}$ One way to meet this recommendation would be to set evidence-informed screening criteria such that patients meeting all criteria are automatically considered for ESD and patients meeting one or more are considered on a case-by-case basis. The inclusion and exclusion criteria (and resulting cohorts of patients) in the studies identified here offer a few examples of criteria that may be useful in this decision-making process. In general, the criteria used by the studies identified in this review target patients with mild-to-moderate functional impairment, good cognitive function, potential to benefit from rehabilitation, and those who live in a suitable environment for rehabilitation.

The benefits of ESD have been most consistently demonstrated among patients with mild-to-moderate functional impairment. In Cochrane's review, a BI of 10 to 20 was used to identify mild-to-moderate impairment ${ }^{3}$; however, the studies identified here suggest that team-coordinated ESD programs are admitting patients with an average BI of $16 / 20$. The study with the most liberal admission procedures was Rudd et al, ${ }^{15}$ in which 1 standard deviation from the mean was still between 11 and 19 on the BI. Automatic admission criteria for ESD could focus on patients with a BI of 16 to 20 , whereas those with a BI of 10 to 15 could be flagged for further consideration. Future research should also explore differences in adjusted outcomes between patients with BI of 10 to 15 and 16 to 19 receiving ESD.

In the studies identified here, nearly all also noted cognitive function in their inclusion/exclusion criteria stating concerns for both the patient's ability to participate in rehabilitation and their safety at home. Holmqvist et al explicitly used an MMSE score of 23 in their inclusion criteria ${ }^{10}$ and two others reported average admission scores of 28 and 21 , respectively. ${ }^{6,15}$ In these three studies, the mean score on admission was 24/30. Similar to BI, the study with the widest dispersion of admission MMSE scores was Rudd et al, ${ }^{15}$ in which 1 standard deviation from the mean ranged from 14 to 28. Cognitive function should be included in all screening criteria for ESD with automatic focus placed on patients with MMSE scores of 23 to 30, as was done by Holmqvist, whereas identifying patients with scores of 14 to 22 for further consideration. No study to date has compared outcomes between patients with high or low cognitive function explicitly, and more research in this area is also warranted.

In addition to patient characteristics, many of the identified studies also included reference to practical considerations such as the availability of a caregiver, suitability of the home environment, and proximity to the hospital. Although caregiver availability has been demonstrated to play a significant role in patient recovery after stroke, ${ }^{21,22}$ suitability of the home environment and proximity to the hospital also represent interesting practical considerations. The importance of flexibility in decisions regarding ESD has regularly been mentioned by ESD experts. ${ }^{4,20}$ Although a patient may meet all of the physical and cognitive characteristics of a typical ESD candidate, few clinicians would feel comfortable discharging patients to an unsuitable home environment (or no home at all). In these cases, the best interest of the patient should be the most important factor in decisions regarding ESD suitability. Care should be taken to document these instances so that they can be studied in detail and analyses can be adjusted appropriately during program evaluation. In a similar way, the distance to a patient's home may practically exclude them from ESD in some instances. Admission criteria for ESD must be developed 
separately for each facility to reflect the unique context of their surrounding geography. Program leaders should also be encouraged to be innovative in the way they provide services. Although provision of ESD in rural settings has been demonstrated to be effective, ${ }^{23}$ other innovative solutions for meeting patient needs such as the use of telemedicine, family participation, and partnership with local care providers should be explored in more detail. However, careful attention should be paid to the key concepts that have made team-coordinated and provided ESD successful, such as early detection of patients, continuity of care, and timely service provision. Well-designed research should be promoted in rural and remote settings to better inform the effectiveness of innovative ESD programs in these areas.

Based on the criteria identified by this review, an algorithm for admission to ESD could look something like the following. Patients with a BI of 16 to 20, MMSE 23 to 30, and a suitable home environment within a predetermined reasonable distance from the hospital could have a discharge to ESD initiated automatically. Patients with a BI of 11 to 20 or an MMSE of 14 to 30 could be flagged for clinical assessment for suitability for admission to ESD, whereas all other patients could be considered on a case-by-case basis. Of course, other measures of functional independence and cognitive function could also be used, but these should be studied further to identify appropriate cutoff scores. This type of system might help to smooth the transition of appropriate patients to ESD and improve system efficiency, while still allowing an appropriate level of flexibility in the admission process.

In addition to clinical decision-making, the results of this review may also be useful for individuals involved in capacity planning for ESD. Although an ESD program that is too small will not be able to meet the needs of all patients who could benefit from its services, a program that is oversized can be seen as a waste of resources. In the studies identified here, the proportion of screened patients who were deemed suitable for admission to ESD ranged from $10 \%$ to $46 \%$ and the duration of ESD ranged from 30 days to 4 months. Interestingly, both of these dropped over time. Studies published since 2000 have included a weighted average of $15 \%$ of acute stroke survivors in their ESD programs and, with the exception of the study by Donnelly et al, ${ }^{9}$ the mean duration of ESD in studies published since 2000 was between 4 and 5 weeks. Pessah-Rasmussen et $\mathrm{al}^{13}$ specifically noted that in their program the mean duration of care dropped from 43 days in 1997 to 30 days in 2005. These trends likely demonstrate a subtle, but important, shift in thinking around ESD. Based on the results of this review, the authors suggest that decision makers anticipate approximately $15 \%$ of stroke survivors as candidates for ESD and consider 4 to 5 weeks as a reasonable average duration of care for planning purposes.

Team-coordinated and delivered ESD after stroke is an important component of an effective stroke rehabilitation system. Cochrane's ESD trialists and Fisher's consensus statement have established a strong foundation with which ESD providers can make informed decisions about program development. This study focused on the way ESD programs are applying this research around the world and offers some perspective on the evolution of ESD care after stroke. Summary of this information may be helpful to health care providers looking to develop or evaluate a regional ESD program. It may also be helpful in informing future research into the topic so that we continue to understand the nuances of providing ESD. This will help to ensure that we continue to provide effective ESD to meet the needs of our patients and provide value for our healthcare systems.

\section{LiMitATIONS}

In the studies identified by this review, the admission criteria and functional outcomes reported were too heterogeneous to allow for any statistical comparison to be performed. For this reason, a summary of published admission criteria was used as an indicator of clinical judgment. Future research is necessary to explore the relationship between the variables used to select patients for ESD and the functional outcomes they achieve.

\section{Conclusions}

Team-coordinated and delivered ESD after stroke is a costeffective way to provide rehabilitation to moderately and mildly impaired patients. A detailed review of ESD programs providing team-coordinated and delivered care suggests some meaningful similarities that can be useful to ESD clinicians and decision makers planning to develop or evaluate an ESD program. Studies suggest that inclusion criteria for ESD should include an objective measure of both physical and cognitive function. BI scores of 16 to 19 and an MMSE greater than 23 could be considered as nearautomatic criteria for admission assuming caregiver availability, suitability of the home environment, and proximity to the hospital are also favourable. Capacity planning for ESD can begin by assuming that approximately $15 \%$ of stroke survivors will be ESD candidates, and that they will require services for 4 to 5 weeks on average. However, flexibility in program planning and ongoing evaluation is recommended and should be incorporated into future research.

\section{ACKNOWLEDGEMENTS AND FUNDING}

This work was made possible by the Canadian Institute for Health Research's Vanier Canada Graduate Scholarship.

\section{Disclosures}

MM, RT, AT, JK, and MS have nothing to disclose.

\section{Supplementary Material}

To view supplementary material for this article, please visit http://dx.doi.org/10.1017/cjn.2015.343

\section{REFERENCES}

1. MacKay J, Mensah GA. The atlas of heart disease and stroke. World Health Organization. [cited 2011] Available from: <http:// www.who.int/cardiovascular_diseases/en/cvd_atlas_15_burden_ stroke.pdf $>$.

2. Teasell R, Foley N, Salter K, Bhogal SK, Jutai J, Speechley M. Evidence-based review of stroke rehabilitation, 16th ed. [cited 2014] Available from: www.ebrsr.com.

3. Fearon P, Langhorne P. Services for reducing duration of hospital care for acute stroke patients. Cochrane Database Syst Rev. 2012;9:CD000443.

4. Fisher RJ, Gaynor C, Kerr M, et al. A consensus on stroke: early supported discharge. Stroke. 2011;42:1392-7.

5. Teasell RW, Foley NC, Bhogal SK, Speechley MR. Early supported discharge in stroke rehabilitation. Top Stroke Rehabil. 2003; 10:19-33.

6. Anderson C, Rubenach S, Mhurchu CN, Clark M, Spencer C, Winsor A. Home or hospital for stroke rehabilitation? results of a 
randomized controlled trial: I: health outcomes at 6 months. Stroke. 2000;31:1024-31.

7. Anderson C, Ni MC, Brown PM, Carter K. Stroke rehabilitation services to accelerate hospital discharge and provide home-based care: an overview and cost analysis. Pharmacoeconomics. 2002;20:537-52.

8. Lindsay P, Bayley M, McDonald A, Graham ID, Warner G, Phillips S. Toward a more effective approach to stroke: Canadian Best Practice Recommendations for Stroke Care. CMAJ. 2008; 178:1418-25.

9. Donnelly M, Power M, Russell M, Fullerton K. Randomized controlled trial of an early discharge rehabilitation service: the Belfast Community Stroke Trial. Stroke. 2004;35:127-33.

10. Holmqvist L, Von KL, Kostulas V, et al. A randomized controlled trial of rehabilitation at home after stroke in southwest Stockholm. Stroke. 1998;29:591-7.

11. Ljungberg C, Hanson E, Lovgren M. A home rehabilitation program for stroke patients. Scand J Caring Sci. 2001;15:44-53.

12. Mayo NE, Wood-Dauphinee S, Cote R, et al. There's no place like home : an evaluation of early supported discharge for stroke. Stroke. 2000;31:1016-23.

13. Pessah-Rasmussen H, Wendel K. Early supported discharge after stroke and continued rehabilitation at home coordinated and delivered by a stroke unit in an urban area. J Rehabil Med. 2009;41:482-8.

14. Rodgers H, Soutter J, Kaiser W, et al. Early supported hospital discharge following acute stroke: pilot study results. Clin Rehabil. 1997;11:280-7.
15. Rudd AG, Wolfe CD, Tilling K, Beech R. Randomised controlled trial to evaluate early discharge scheme for patients with stroke. BMJ. 1997;315:1039-44.

16. Wade DT. Research into the black box of rehabilitation: the risks of a type III error. Clin Rehabil. 2001;15:1-4.

17. Nir Z, Zolotogorsky Z, Sugarman H. Structured nursing intervention versus routine rehabilitation after stroke. Am J Phys Med Rehabil. 2004;83:522-9.

18. Kirkevold M. The role of nursing in the rehabilitation of stroke survivors: an extended theoretical account. ANS Adv Nurs Sci. 2010;33:E27-40.

19. Rizzo VM. Social work support services for stroke patients: interventions and outcomes. Soc Work Health Care. 2006;43:33-56.

20. Chouliara N, Fisher RJ, Kerr M, Walker MF. Implementing evidence-based stroke Early Supported Discharge services: a qualitative study of challenges, facilitators and impact. Clin Rehabil. 2014;28:370-7.

21. Tanwir S, Montgomery K, Chari V, Nesathurai S. Stroke rehabilitation: availability of a family member as caregiver and discharge destination. Eur J Phys Rehabil Med. 2014;50:355-62.

22. Pereira S, Foley N, Salter K, et al. Discharge destination of individuals with severe stroke undergoing rehabilitation: a predictive model. Disabil Rehabil. 2014;36:727-31.

23. Askim T, Rohweder G, Lydersen S, Indredavik B. Evaluation of an extended stroke unit service with early supported discharge for patients living in a rural community. A randomized controlled trial. Clin Rehabil. 2004;18:238-48. 